\title{
Effect of acid pretreatment of the plated substrate on the hardness of the carbon plating film formed by using a molten salt electrochemical process
}

\author{
K. Tanaka ${ }^{1}$, Y. Okumura ${ }^{1}$, H. Kurooka ${ }^{1}$, T. Katayama ${ }^{1}$, \\ A. Yukawa ${ }^{2} \&$ Y. Ueda ${ }^{2}$ \\ ${ }^{1}$ Department of Biomedical Engineering, Doshisha University, Japan \\ ${ }^{2}$ Nihon Proton Co., Ltd, Japan
}

\begin{abstract}
Diamond-like carbon (DLC) has excellent features in low friction and wear resistance, so its application is expanding rapidly as surface treatment of the sliding elements of automotive machine parts. In recent years, pollutionprevention has been drawing attention, and for this purpose, the use of lubricating oil has been drastically reduced and low friction surface treatment has become popular in industry. In order to overcome the drawbacks of DLC, such as expensive film and time consuming processes, carbon film plating technology has been developed by using the molten salt electrochemical process. Although the formation of carbon film on stainless steel substrate and the influence on the morphology of the film in electrolytic condition is becoming clear, the deposition of the carbon film using molten salt electrochemical process has the problem of poor adhesion between the substrate and the film in the present situation. In this paper, the effect of pretreatment of acid on the substrate by using a molten salt electrochemical process was investigated. A very smooth surface was obtained by rinsing with hydrochloric acid compared with sulfuric acid in the pretreatment process. When the substrate was pretreated with hydrochloric acid, a carbon film having a high film hardness and high density was obtained.
\end{abstract}

Keywords: carbon film, molten salt electrochemical process, pretreatment, PR electrolysis, hydrochloric acid, sulfuric acid. 


\section{Introduction}

In recent years, the use of lubricating oil is trying to avoid in sliding elements of automotive and machine parts because of as much as saving energy by low friction and resource by extending life of parts to reach a target of creating pollution free environment, which is very necessary requirement for all of our life [1]. Therefore, in order to realize the unlubricated sliding, the development of a hard film technology for depositing a high-hardness film of several micrometers on the surface of the substrate has been advanced progressively. Diamond-like carbon (DLC) has attracted attentions among them [2-4]. DLC has excellent features in low friction and wear resistance, so its application as surface treatment of the sliding elements such as automotive parts and machine parts is expanding rapidly. However, since film-forming method of DLC is still now using with vacuum method and it has also some drawbacks such as complex, expensive, high-energy, difficult in maintenance and time-consuming in the process [5-7]. In order to overcome these problems, as new film alternative to DLC film, carbon film plating technology has been developed by using the Molten Salt Electrical Process (MSEP) by Ito [8] and Ito and Nohira [9]. Since MSEP is a simple process with low cost, so it can be examined thoroughly for finding easy method of mass production. Although the formation of carbon film on stainless steel substrate and the influence on the morphology of the film in electrolytic condition is becoming clear, however, the deposition of the carbon film using molten salt electrochemical process has a problem of poor adhesion between the substrate and the film in the present situation. In addition, since there is a problem that film hardness is low for alternative materials of DLC, so it is necessary to develop a method to improve the adhesion and the film hardness. In this paper, for the purpose of clarifying the effect of pretreatment with acid of the plated substrate on properties of the carbon plating film formed by using a molten salt electrochemical process, the effect of pretreatment of the substrate with acid on the hardness of the carbon plating film is investigated by performing nano indentation testing, Raman spectra analysis and morphology observation on the assessment of substrate and the film.

\section{Materials and experimental methods}

\subsection{Film deposition method of the carbon plating}

SUS304 $(50 \times 20 \times 0.5 \mathrm{~mm})$ with a mirror polished surface was used as the substrate. Fig. 1 shows experimental apparatus used for molten salt electrochemical process. For the plating bath, lithium chloride $(59 \mathrm{~mol} \%)$ and potassium chloride (41 mol\%) were used as molten salts, and potassium carbonate $(4 \mathrm{~mol} \%)$ was used as the origin of carbon. Electrolyzing by dissolving potassium carbonate in the molten salt, carbon film is formed on the cathode surface. The substrates were immersed in the defatting liquid at $60^{\circ} \mathrm{C}$ for twenty minutes and polished in order to remove the degreasing liquid and subsequently, the substrates were water-cleaned, electrolytically degreased at $3 \mathrm{~A} / \mathrm{dm}^{2}$ for one 


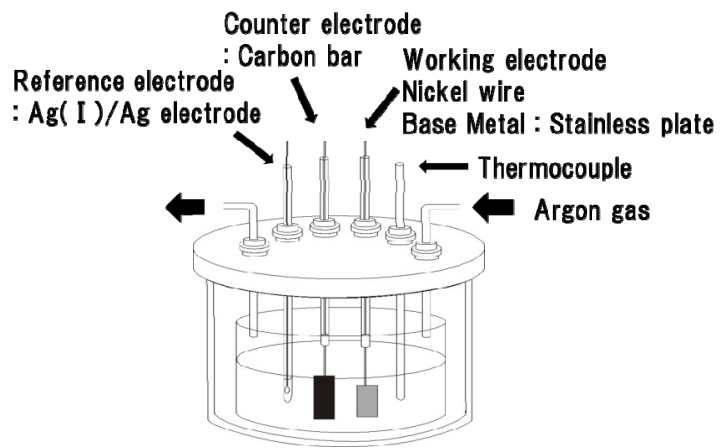

Figure 1: Experimental apparatus for schematic diagram.

minute and again water-cleaned to remove any impurity of the surface. Thereafter, pretreatment with acid using hydrochloric acid and sulfuric acid as the acid activators was done in order to remove the surface oxide film of the substrates. The temperatures for acid activation were set at 25 and $50^{\circ} \mathrm{C}$, the concentrations for acid activation were set at 10, 25 and 50\%, and the treatment was done under six conditions for each against sulfuric acid and hydrochloric acid. All processing time was set for three minutes. After pretreatment with acid, plating process was performed using periodically reversed (PR) electrolysis. PR electrolysis is a method of electrolyzing of changing the current direction at a constant period. By causing the reverse electrolysis to a position where the reaction proceeds preferentially in the positive electrolyte, a flat-smooth film is obtained by growth of metal deposit with suppressing local precipitation [10]. As shown in Fig. 2, electrolysis condition of PR electrolysis was as follows: the ratio of times between positive current and negative current was $2: 5$, electric current was $0.6 \mathrm{~A}$ and the total quantity of electricity in the plating process was $2500 \mathrm{C} / \mathrm{cm}^{2}$. Ultrasonic cleaning was conducted after plating process.

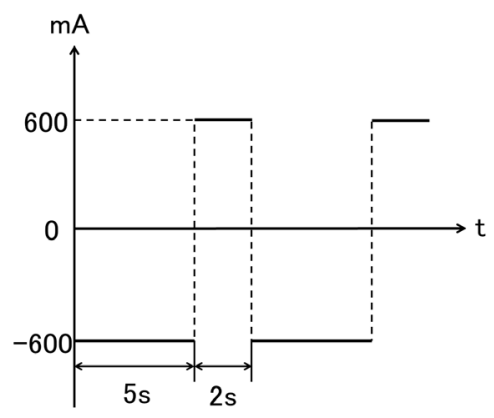

Figure 2: Electrolysis condition of PR electrolysis. 


\subsection{Morphology observation of the carbon film}

Surface morphology of the plated film was observed with a scanning electron microscopy (SEM, JSM-6390LT) and particle size of plated carbon film on the substrate was measured at fifteen arbitrary measuring lines. In addition, mean surface roughness $R_{a}$ of the substrate pretreated with acid and plated film was measured with fine shape measuring apparatus (Alpha-Step IQ, KLA Tencor) at five arbitrary measuring lines under the following conditions: measurement distance was $500 \mu \mathrm{m}$ and measurement time was for 10 seconds. Carbon plated film was analyzed with laser Raman spectroscopy (NSR-2000, Jasco) and the ratio between graphite structure and diamond structure was calculated. The hardness of the plating film was measured with nano indentation testing equipment (Tribo Indenter, HYSITRON Inc.) The setting in performing indentation was to reach a maximum indentation load in 5 seconds, after this the tip of the indenter was hold for 2 seconds from the peak time and then unloaded over 5 seconds. Maximum indentation load was set at $100 \mu \mathrm{N}$.

\section{Results and discussions}

Reaction formulae of iron oxide and hydrochloric acid are described below.

$$
\begin{gathered}
\mathrm{Fe}+2 \mathrm{HCl} \rightarrow \mathrm{FeCl}_{2}+\mathrm{H}_{2} \\
\mathrm{FeO}+2 \mathrm{HCl} \rightarrow \mathrm{FeCl}_{2}+\mathrm{H}_{2} \mathrm{O} \\
\mathrm{Fe}_{2} \mathrm{O}_{3}+6 \mathrm{HCl} \rightarrow 2 \mathrm{FeCl}_{3}+3 \mathrm{H}_{2} \mathrm{O}
\end{gathered}
$$

Reaction formulae of iron oxide and sulfuric acid are described below.

$$
\begin{aligned}
\mathrm{Fe}+\mathrm{H}_{2} \mathrm{SO}_{4} & \rightarrow \mathrm{FeSO}_{4}+\mathrm{H}_{2} \\
\mathrm{FeO}+\mathrm{H}_{2} \mathrm{SO}_{4} & \rightarrow \mathrm{FeSO}_{4}+3 \mathrm{H}_{2} \mathrm{O} \\
\mathrm{Fe}_{2} \mathrm{O}_{3}+3 \mathrm{H}_{2} \mathrm{SO}_{4} & \rightarrow \mathrm{Fe}_{2}\left(\mathrm{SO}_{4}\right)_{3}+3 \mathrm{H}_{2} \mathrm{O}
\end{aligned}
$$

It is noted that based on the equation (1) and the equation (4), hydrogen generated by the interaction hastens the progress of acid activity of the metal surface $[11,12]$. Fig. 3 shows roughness of the substrate surface after acid pretreatment. The substrate which was pretreated with sulfuric acid at $50^{\circ} \mathrm{C}$ and $25 \%$ in concentration was rougher than other conditions. It has been reported that sulfuric acid can dissolve a substrate more than hydrochloric acid when the amount of reactions per one mol by hydrochloric acid and sulfuric acid, which are shown in the equation (1) and the equation (4), are same [13, 14]. It is also reported that due to larger hydrogen gas generated during pretreatment with sulfuric acid than hydrochloric acid, delamination makes more likely to be caused for pretreatment with sulfuric acid [14].

Figs 4 and 5 show results of Raman spectra analysis of the carbon film plated on the substrates which were pretreated with hydrochloric acid and sulfuric acid. Table 1 shows the peak position of $G$ band and Table 2 shows $\mathrm{I}_{\mathrm{D}} / \mathrm{I}_{\mathrm{G}}$ ratio for each pretreatment condition. Under the same temperature and the same concentration, as compared with sulfuric acid, the peak position of $\mathrm{G}$ band of the film pretreated 


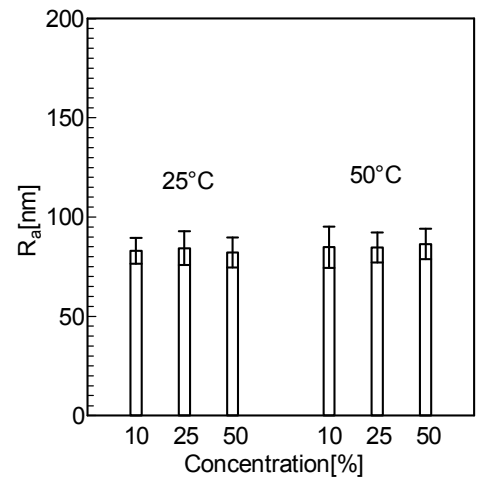

(a) Hydrochloric acid

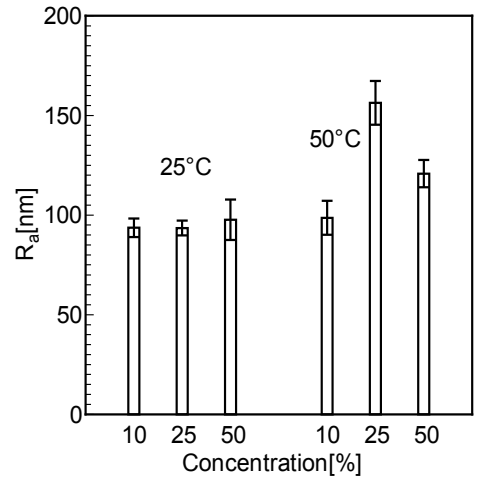

(b) Sulfuric acid

Figure 3: Roughness of the substrate after acid pretreatment.

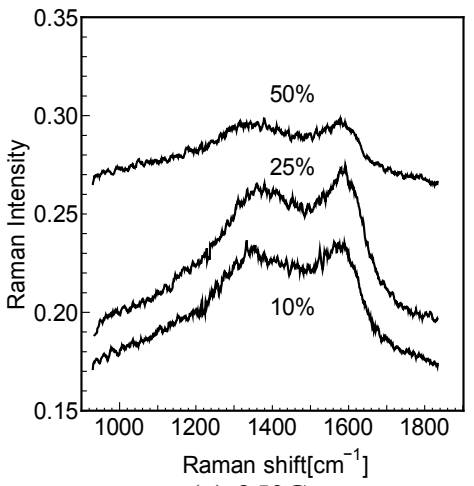

(a) $25^{\circ} \mathrm{C}$

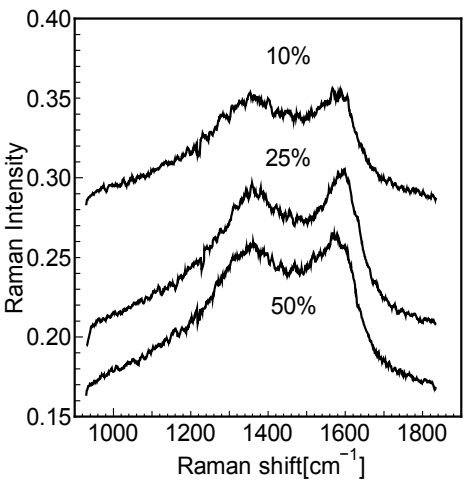

(b) $50^{\circ} \mathrm{C}$

Figure 4: Raman spectra analysis of the carbon film plated on the substrate pretreated with hydrochloric acid.

with hydrochloric acid has higher wavenumber and $\mathrm{I}_{\mathrm{D}} / \mathrm{I}_{\mathrm{G}}$ is relatively small. In the carbon film plated on the substrates pretreated with sulfuric acid at $25^{\circ} \mathrm{C}$ and pretreated with hydrochloric acid at $25^{\circ} \mathrm{C}$ and $50^{\circ} \mathrm{C}$, the peak position of $\mathrm{G}$ band at $25 \%$ in concentration has higher wavenumber. For DLC film, mechanical properties are depending on the composition ratio of $\mathrm{sp}^{2}, \mathrm{sp}^{3}$ and inclusions. Generally, the film becomes harder when diamond nature appears as $\mathrm{sp}^{3}$ ratio increases and hydrogen decreases. In addition, graphite nature strongly appears when $\mathrm{sp}^{2}$ ratio increases [4-6].

Figs 6 and 7 show results of nano indentation testing. Hardness of the film plated on the substrates which was pretreated with hydrochloric acid is high compared with that with sulfuric acid. For the carbon film plated on the substrates pretreated with sulfuric acid at $25^{\circ} \mathrm{C}$ and pretreated with hydrochloric 


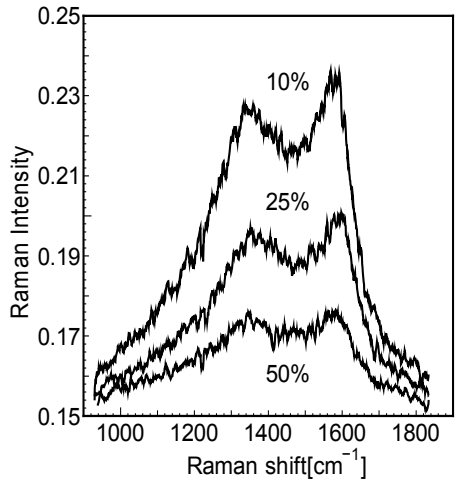

(a) $25^{\circ} \mathrm{C}$

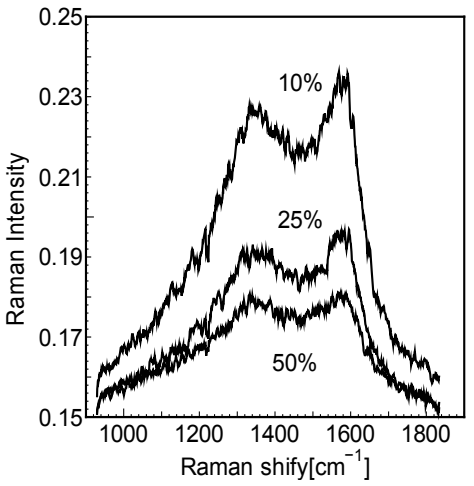

(b) $50^{\circ} \mathrm{C}$

Figure 5: Raman spectra analysis of the carbon film plated on the substrate pretreated with sulfuric acid.

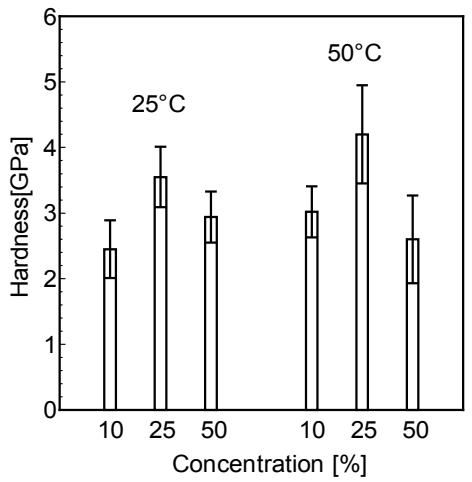

Figure 6: The result of nano indentation testing of the carbon coating plated on the substrates pretreated with hydrochloric acid.

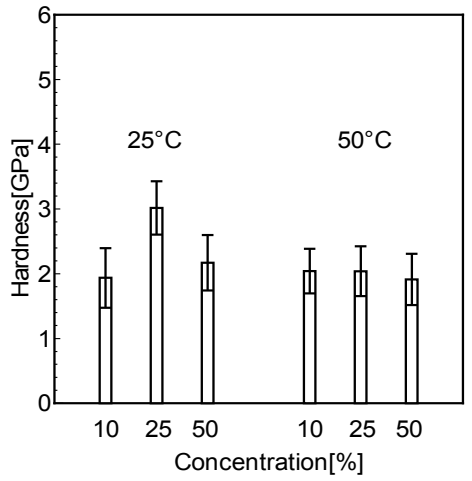

Figure 7: The result of nano indentation testing of the carbon coating plated on the substrates pretreated with sulfuric acid. 
acid at $25^{\circ} \mathrm{C}$ and $50^{\circ} \mathrm{C}$, the hardness is high compared with the other concentration condition. In the previous studies, it is reported that when the amount of contained hydrogen decreases, $G$ band moves to the side of high wavenumber and $\mathrm{I}_{\mathrm{D}} / \mathrm{I}_{\mathrm{G}}$ becomes small and the hardness becomes higher $[15,16]$. Considering from the results of Raman spectroscopy analysis shown in Tables 1 and 2 and the results of nano indentation testing shown in Figs. 6 and 7, same tendency was observed in our study.

Figs 8 and 9 show SEM images of the carbon film plated on the substrates pretreated with hydrochloric and sulfuric acid. The surface which was pretreated with sulfuric acid has many cracks and detachments. As described before, the hydrogen gas, generated during the acid pretreatment of the substrate, enhance the delamination of carbon film.

Table 3 shows measurement results of the average particle size of carbon film. Particle size of the film which was pretreated with hydrochloric acid was smaller than that which was pretreated with sulfuric acid. Particle size of the film which was pretreated with hydrochloric acid was small when temperatures were at $25^{\circ} \mathrm{C}$ and at $50^{\circ} \mathrm{C}$ and the concentration was at $25 \%$. PR electrolysis used in this study is a method of alternately repeating the reverse current and the deposition

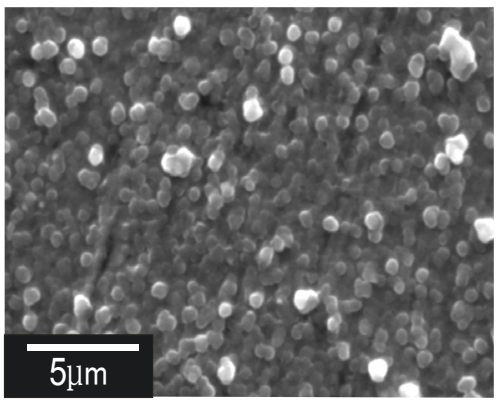

(a) $25^{\circ} \mathrm{C}$

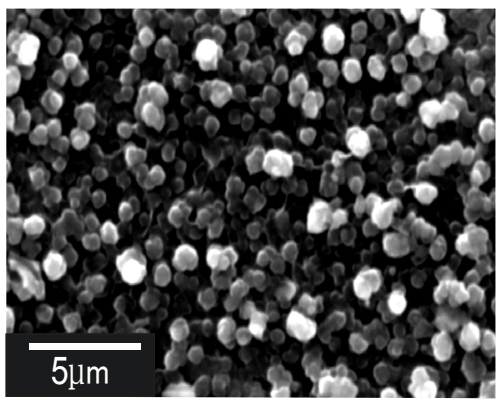

(c) $50^{\circ} \mathrm{C}$

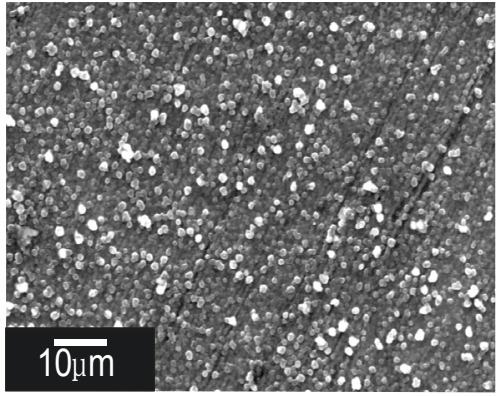

(b) $25^{\circ} \mathrm{C}$

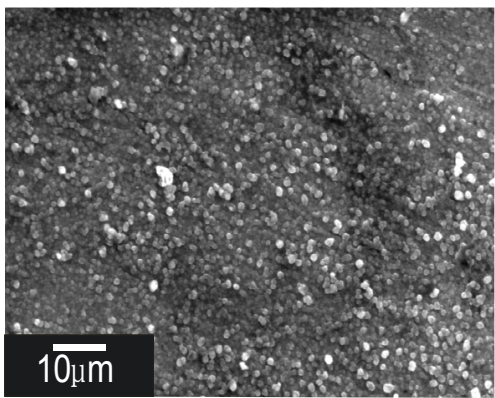

(d) $50^{\circ} \mathrm{C}$

Figure 8: Coating surface plated on the substrate pretreated with hydrochloric acid. 


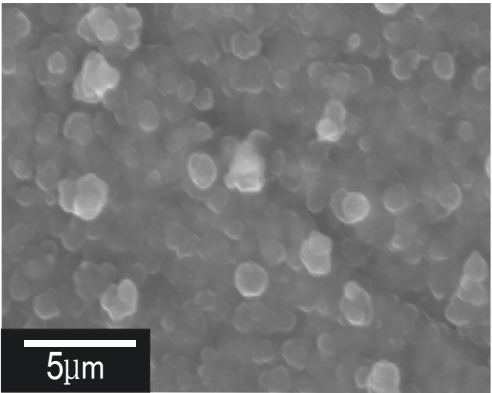

(a) $25^{\circ} \mathrm{C}$

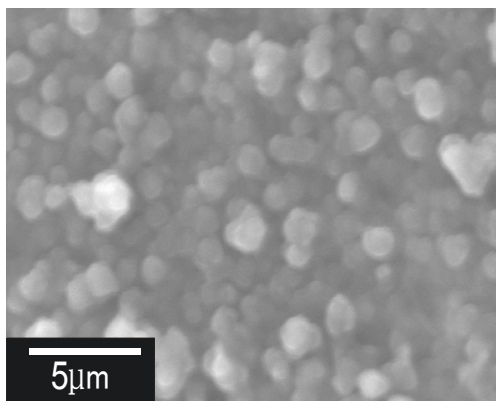

(c) $50^{\circ} \mathrm{C}$

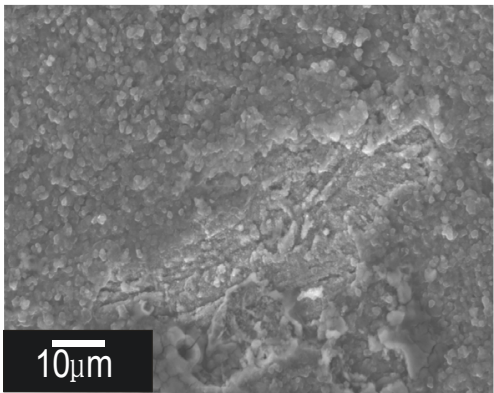

(b) $25^{\circ} \mathrm{C}$

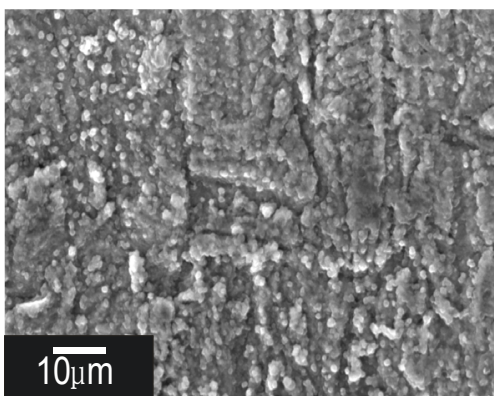

(d) $50^{\circ} \mathrm{C}$

Figure 9: Coating surface plated on the substrate pretreated with sulfuric acid.

current. The nucleus which is grown up becomes small with decomposition when applying the reverse current and can form the film smoothly on applying the electric current again. It has been reported that when forming a coating on the rough substrate, the coating with large particle size is likely to be produced due to the concentration of the electron at the convex area. Therefore, the substrate with the smooth surface is required to obtain the film with small particle size. In our case, the substrate which was pretreated with hydrochloric acid has smoother surface and resulting smaller particle size than that with sulfuric acid.

Table 1: Peak position of $\mathrm{G}$ band.

\begin{tabular}{|c|c|c|c|c|c|c|}
\hline $\begin{array}{c}\text { Temperature } \\
\text { at acid } \\
\text { activation }{ }^{\circ} \mathrm{C}\end{array}$ & \multicolumn{3}{|c|}{25} & \multicolumn{3}{|c|}{50} \\
\hline $\begin{array}{c}\text { Concentration } \\
\text { at acid } \\
\text { activation \% }\end{array}$ & 10 & 25 & 50 & 10 & 25 & 50 \\
\hline $\mathrm{HCl}$ & 1573 & 1582 & 1575 & 1572 & 1586 & 1574 \\
\hline $\mathrm{H}_{2} \mathrm{SO}_{4}$ & 1568 & 1577 & 1571 & 1568 & 1566 & 1571 \\
\hline
\end{tabular}


Table 2: Ratio of $\mathrm{I}_{\mathrm{D}} / \mathrm{I}_{\mathrm{G}}$.

\begin{tabular}{|c|c|c|c|c|c|c|}
\hline $\begin{array}{c}\text { Temperature } \\
\text { at acid } \\
\text { activation }{ }^{\circ} \mathrm{C}\end{array}$ & \multicolumn{2}{|c|}{25} & \multicolumn{3}{|c|}{50} \\
\hline $\begin{array}{c}\text { Concentration } \\
\text { at acid } \\
\text { activation \% }\end{array}$ & 10 & 25 & 50 & 10 & 25 & 50 \\
\hline $\mathrm{HCl}$ & 5.82 & 5.23 & 5.73 & 6.17 & 5.61 & 6.23 \\
\hline $\mathrm{H}_{2} \mathrm{SO}_{4}$ & 6.24 & 5.75 & 6.31 & 6.28 & 6.37 & 6.18 \\
\hline
\end{tabular}

Table 3: Results of measured average particle size of carbon film.

\begin{tabular}{|c|c|c|c|c|c|c|c|}
\hline \multicolumn{2}{|c|}{$\begin{array}{c}\text { Temperature at acid } \\
\text { activation }{ }^{\circ} \mathrm{C}\end{array}$} & \multicolumn{3}{|c|}{25} & \multicolumn{3}{c|}{50} \\
\hline $\begin{array}{c}\text { Concentration at acid } \\
\text { activation \% }\end{array}$ & 10 & 25 & 50 & 10 & 25 & 50 \\
\hline \multirow{2}{*}{$\begin{array}{c}\text { Average } \\
\begin{array}{c}\text { particle size of } \\
\text { carbon film } \mu \mathrm{m}\end{array}\end{array}$} & $\mathrm{HCl}$ & 1.2 & 1.0 & 1.2 & 1.3 & 1.0 & 1.4 \\
\cline { 2 - 8 } & $\mathrm{H}_{2} \mathrm{SO}_{4}$ & 1.5 & 1.3 & 1.5 & 1.6 & 1.5 & 1.6 \\
\hline
\end{tabular}

\section{Conclusion}

The effect of pretreatment of the substrate with acid on the hardness of the carbon plating film formed by using a molten salt electrochemical process is investigated by performing nano indentation testing, Raman spectra analysis and morphology observation on the assessment of substrate and the film. The investigation yields the following conclusions:

(1) The substrate which was pretreated with hydrochloric acid was smoother surface compared to that with the sulfuric acid.

(2) Carbon film having higher film hardness can be obtained when the substrate was pretreated with hydrochloric acid than sulfuric acid.

\section{References}

[1] Ikenaga, M. \& Ikenaga, K., Properties and Application of DLC Coatings, Journal of the Surface Finishing Society of Japan, Vol. 53, No. 11, pp. 711-714, 2002. 
[2] Zhang, S., Sun, D., Fu, Y. \& Du, H., Toughening of hard nanostructural thin films: a critical review, Surface \& Films Technology, Vol. 198, pp. 28, 2005.

[3] Vetter, J., Ackerman, C., Meunier, F., Jarry, O., Schumacher, D. \& Erkens, G., High performance hard carbon films (diamond-like films) Vol. 24, pp. 18-23, 2012.

[4] Robertson, J., Diamond-like amorphous carbon, Material Science and Engineering, pp. 129-289, 2002.

[5] Jiang, X., Reichelt, K. \& Stritzker, B., Mechanical properties of a-C:H films prepared by plasma decomposition of $\mathrm{C}_{2} \mathrm{H}_{2}$, Journal of Applied Physics, Vol. 68, No. 3, pp. 1018-1022, 1990.

[6] Marques, F.C., Lacerda, R. G., Odo, G. Y. \& Lepienski, C. M., On the hardness of a-C:H films prepared by methane plasma decomposition, Thin Solid Films, pp. 113-117, 1998.

[7] Lu, F. X., Zhong, G. F., Sun, J. G., Tang, W. Z., Wang, J. J., Li, C. H., Zang, J. M., Pan, C. H., Tang, C. X., Lo, T. L. \& Zhang, Y. G., A new type of DC arc plasma torch for low cost large area diamond deposition, Diamond and Related, pp. 737-741, 1998.

[8] Y. Ito, Formation of a carbon film by the molten salt electrochemical process and its applications, TANSO, pp. 144-151, 2011.

[9] Ito, Y.\& Nohira, T., Surface Modification by Molten Salt Electrochemical Process, Surface Technology, pp. 8-12, 1998.

[10] Yukawa, A., Ueda, Y., Adachi, Y., Tanaka, K., Katayama, T., Ohata, S., Tsujimura, H. \& Ito, Y., Electrochemical formation of carbon film utilizing cathodic reduction of carbonate ions in a molten chloride: Effect of PR electrolysis, Journal of the Surface Finishing Society of Japan, Vol. 65, No. 1, pp. 41-46, 2014.

[11] Nihira, N. \& Mitsuo, A., Hazimeteno Hyoumenn Syori Gizyutsu, Kogyo Chosakai Publishing, 2001.

[12] Mamiya, H., Hyoumenn Seizyou Gizyutsu, pp. 67-75, Makisyoten, 1993

[13] Nishimura, R., Araki, M. \& Kudo, K., The Selective Dissolution of SUS304 and SUS316 Austenitic Stainless Steels in a Hydrochloric Acid Solution, J. Japan Inst. Metals, Vol. 47, No. 5, pp. 413-419, 1983.

[14] Kase, H., Saishin Mekki Gizyutsu, Sangyoutosyo, pp. 66-93, 1983.

[15] Takeda, M., \& Murakami, M., Properties and structural evaluation of the diamond-like carbon (DLC) film, The TRC News, No.108, pp. 15-18, 2009.

[16] Horiuchi, T., Yoshida, K., Kaneko, S., Kato, C., Kano, M., Kumagai, M. \& Suzuki, T., Relationship between mass density and hardness, Raman spectrum of DLC films deposited by different film methods and conditions, Kanagawa Industrial Technology Center Annual Reports, No. 17, pp. 9-12, 2011. 